To the Editors:

\title{
Informed consent in clinical practice: a descriptive cross-sectional study of patient perceptions at the National Hospital, Sri Lanka
}

Informed consent, an important component of medical ethics, is based on the principle of autonomy and enables patients to participate in decisions pertaining to their health [1]. Although consent is considered to be implied when a patient seeks treatment, the doctor is ethically and legally bound to obtain consent before clinical examination, investigations and interventions [2].

There has been growing interest in medical ethics worldwide during the latter half of the 20th century with debates on vegetative states, euthanasia and clinical trials [3]. Medical ethics is now incorporated into undergraduate and postgraduate medical curriculums, and professional medical bodies have recognised its importance by laying down ethical guidelines for practitioners [4]. Studies done worldwide to assess patients' views regarding informed consent give varying results but the majority show that patients still prefer a passive role. This study aims to describe the awareness of Sri Lankan patients on the necessity to obtain informed consent .

The study was done in a single institution (National Hospital of Sri Lanka) over a period of two months (1 December 2004 - 31 January 2005). A small sample (101) participated in the research. Self-administered questionnaires, pretested and validated, were distributed among 25 inpatients and 76 outpatients using a stratified randomised sampling based on inpatients and outpatient statistics of the hospital.

Ninety seven completed the questionnaire, and 4 were excluded because of incomplete responses. Seventy five $(77.3 \%)$ of the 97 patients included in the study expressed the need to obtain consent in clinical investigations and interventions. Table 1 presents the views of 95 patients on patient participation in clinical decision making.

When Chi-square analysis was used, no significant differences were found in the awareness of the necessity to obtain informed consent between men and women, and inpatient and outpatient groups. However, those who had an education level $\geq$ GCE Ordinary Level were significantly more aware of the necessity to obtain informed consent $(\mathrm{p}<0.05)$.

The results of this study indicate that the majority of patients are aware of the need for informed consent in clinical investigations and interventions. A significant percentage of them were aware of the need for written consent for surgery and anaesthesia. Many were also aware that consent should be obtained for a procedure even if it is repeated during the same hospital stay, even by the same doctor.

Many patients are also of the view that patient participation is necessary for clinical decision making. This is contrary to the findings of a survey in Japan where $60 \%$ of respondents felt that the physician should make the final decision for the patient [5].

Our findings indicate that Sri Lanka is shifting from the traditional paternalistic approach of physicians to a more patient-centred relationship where the patient wants to actively participate in clinical decisions.

Table 1. Patient views on participation by them in clinical decision making

Frequency (\%)

Doctor should make the decision and the patient's participation is unnecessary

Doctor should make the decision, but patient's wishes should also be considered

Patients should make decisions after having necessary explanations from doctors

Decisions should be made collectively by the patient and family after having the necessary explanations from the doctor

$37(38.9)$

\section{References}

1. Beauchamp TL, Childress JF. Principles of Biomedical Ethics. 5th ed. New York: Oxford University Press, 2001.

2. LaFollette H. Ethics In Practice; An Anthology. Massachusetts: Blackwell Publishers Ltd., 1997.

3. Applebaum PS, Lidz CW, Miesel A. Informed Consent: Legal Theory and Clinical Practice. New York: Oxford University Press, 1987.

4. General Medical Council. Seeking Patients' Consent: The Ethical Considerations. London: GMC, 1998.

5. Atushi A. Barriers to informed consent in Japan. Eubios Journal of Asian and International Bioethics 1996; 6: 91-3.

Nadeeka K Rathnamala, Research Assistant, Health Development and Research Program, University of Colombo. Research Grant from the Ethical Review Committee of the Faculty of Medicine, Colombo, Sri Lanka.

Correspondence: e-mail: <nadeekaoffice@yahoo.com>. (Competing interests: none declared). Received 14 March 2005 and revised version accepted 28 May 2005. 